\title{
Cystic Angiomatous Meningioma: A Diagnostic Dilemma
}

\author{
Sumit Bansal ${ }^{1}$ Ashok Kumar Mahapatra ${ }^{1}$ Susama Patra ${ }^{2}$
}

${ }^{1}$ Department of Neurosurgery, All India Institute of Medical Sciences, Bhubaneswar, Odisha, India

2 Department of Pathology and Laboratory Medicine, All India Institute of Medical Sciences, Bhubaneswar, Odisha, India

Indian J Neurosurg 2016;5:106-109.
Address for correspondence Sumit Bansal, MCh, Room No. 419, Department of Neurosurgery, All India Institute of Medical Sciences, Bhubaneswar, Odisha 751019, India (e-mail: drsumitbansal@gmail.com).

\begin{abstract}
Keywords

- supratentorial

- angiomatous meningioma

- cystic meningioma

Cyst formation in meningioma is rare and furthermore, cyst formation in angiomatous variant of meningioma is extremely rare. Here, we are reporting an unusual angiomatous variant of meningioma with extensive cystic changes mimicking supratentorial hemangioblastoma. The tumor was detected in a 42-year-old woman who presented with left-sided hemiparesis. Magnetic resonance imaging of the brain revealed a large-sized cystic tumor with a contrast-enhancing nodule in the right posterior frontal region. Total excision of the tumor was achieved and left hemiparesis improved.
\end{abstract}

\section{Introduction}

Differential diagnosis of a solid cystic lesion in supratentorial location includes glioma, ${ }^{1}$ meningioma, ${ }^{2}$ metastatic tumor, ${ }^{3}$ or hemangioblastoma. ${ }^{1}$ Cystic meningioma is relatively a rare tumor. $^{2}$ Among various histological variants of meningioma, the meningothelial type most frequently demonstrates cystic changes. ${ }^{3}$ Richly vascularized meningiomas of the angiomatous type were reported only in a few cases $^{4}$ and literature concerning the angiomatous variant of meningioma with cyst formation is limited. ${ }^{5-7}$ The authors are presenting a case of angiomatous meningioma in association with prominent cystic changes mimicking supratentorial hemangioblastoma along with a literature review.

\section{Case Report}

A 42-year-old woman presented with left-sided hemiparesis (Medical Research Council grade 4/5). Computed tomographic (CT) scan of the head showed a solid cystic mass in the right posterior frontal region. Magnetic resonance imaging (MRI) of the brain revealed a large solid cystic tumor in the convexity of the right posterior frontal region. The nodule was isointense on
T1-weighted images (T1WI), hyperintense on T2-weighted images (T2WI), and homogeneously enhancing on contrast. Peritumoral cyst was hyperintense on T1WI and T2WI and not enhancing on contrast. The nodule was showing restriction on diffusion-weighted imaging ( - Fig. 1). There was no dural tail.

After a frontal craniotomy, a dural attachment of the lesion was found. The cyst contained xanthochromic fluid. The nodule was grayish white, soft to firm, and friable with attachment to overlying dura. The tumor was excised completely with its dural attachment. Postoperative CT head showed total excision of lesion (-Fig. 2).

Histopathology was suggestive of an angiomatous meningioma with extensive cystic changes (World Health Organization [WHO] grade I). Tumor tissue was composed of neoplastic meningothelial cells in sheets and syncytium. Tumor cells were polygonal with moderate eosinophilic cytoplasm and nuclei with granular and open chromatin. Vascular channels of varied caliber and focal lipomatous change were seen interspersed among the tumor cells. The tumor cells showed diffuse membrane positivity for epithelial membrane antigen. Low MIB-1 index of $1.5 \%$ was also noted. Synaptophysin, S100, and progesterone receptor were negative (-Fig. $\mathbf{3}$ ). received

July 31,2015

accepted after revision

December 23, 2015

published online

June 8, 2016
DOI http://dx.doi.org/

$10.1055 / \mathrm{s}-0036-1581981$. ISSN 2277-954X. (c) 2016 Neurological Surgeons' Society
of India

License terms 


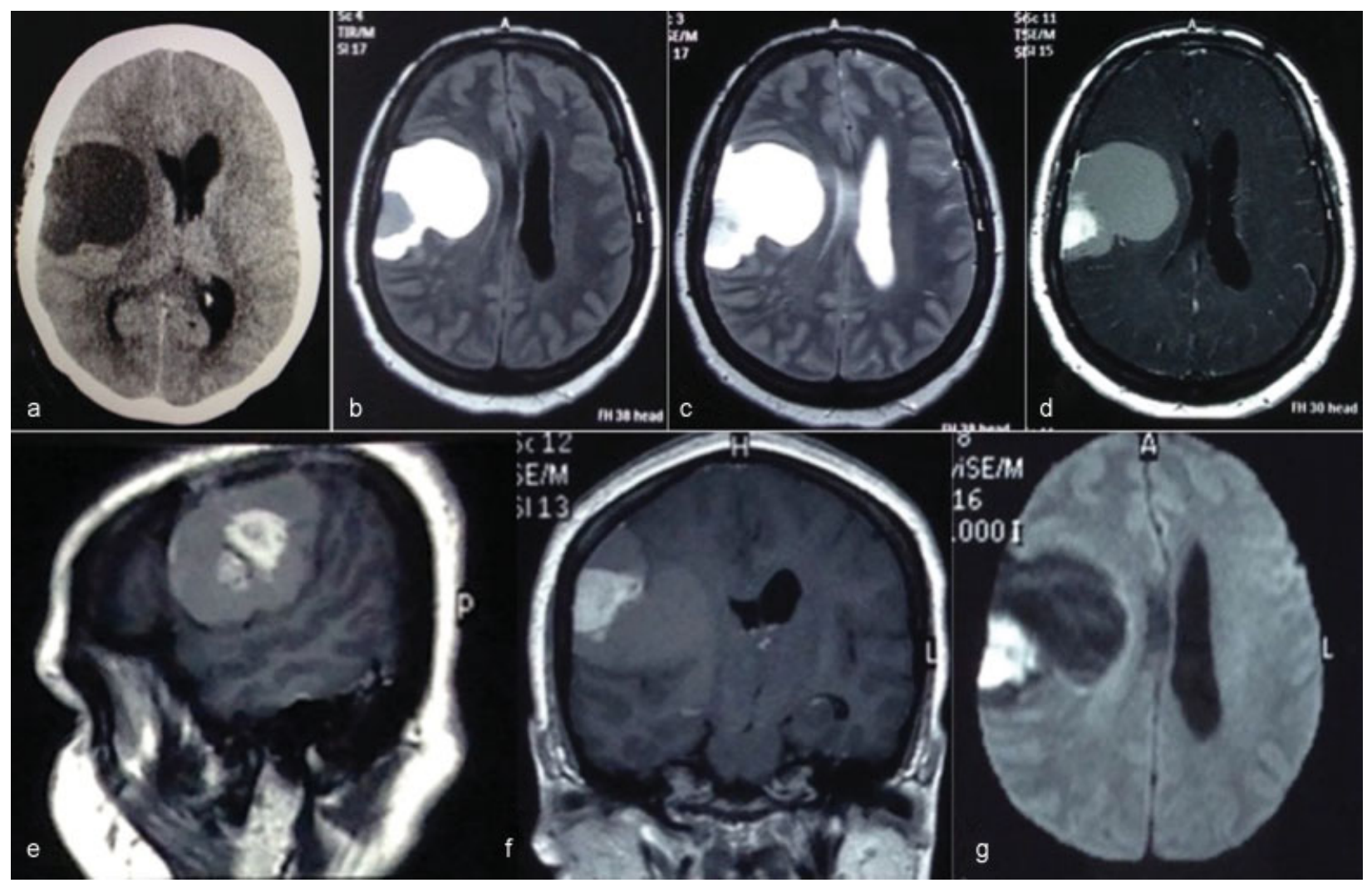

Fig. 1 Solid cystic mass in right posterior frontal region: hypodense lesion on axial view (a) on noncontrast CT head, isointense nodule with hyperintense cyst on axial T1WI (b), hyperintense nodule with hyperintense cyst on axial T2WI (c), enhancing nodule with hyperintense cyst on contrast T1WI (axial [d], sagittal [e], and coronal [f] images), diffusion restriction of nodule on diffusion-weighted image (g). CT, computed tomography; T1WI, T1-weighted image; T2WI, T2-weighted image.

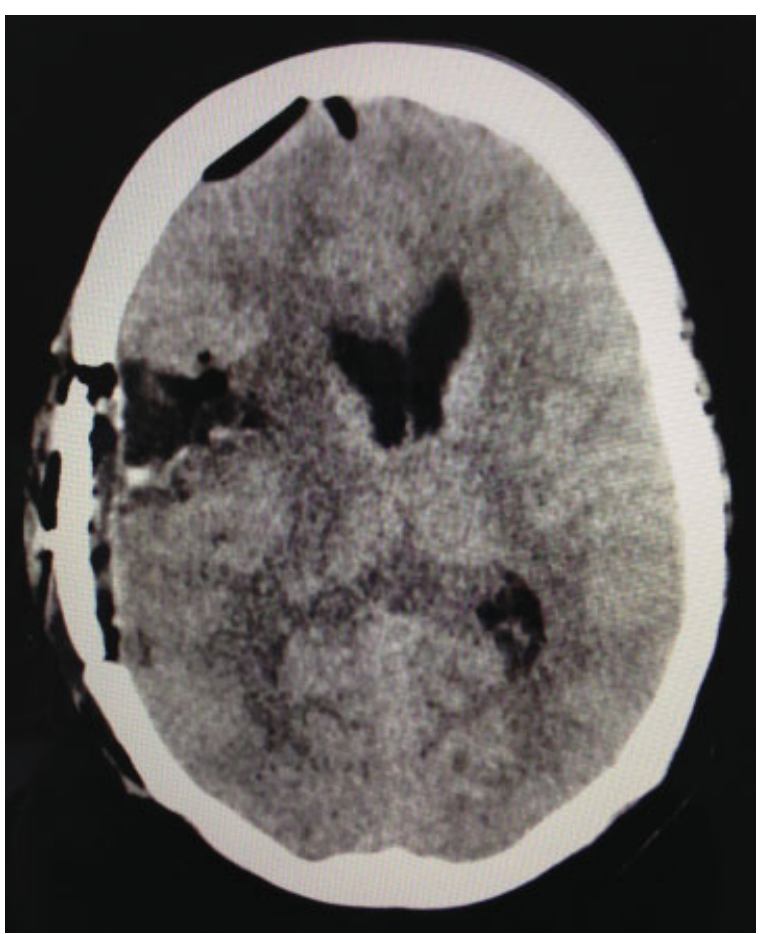

Fig. 2 Postoperative CT head showing gross total resection of tumor. $\mathrm{CT}$, computed tomography.
The postoperative period was uneventful and the patient was discharged in a satisfactory condition with improvement in neurological deficits.

\section{Discussion}

The incidence of cystic meningiomas ranges from 2 to $7.3 \%{ }^{4}$ Different secondary cystic lesions of the tumors with both intratumoral and peritumoral locations are included in cystic meningioma. ${ }^{1}$ Angiomatous meningiomas have the histological and clinical features of benign meningiomas (WHO grade I ${ }^{8}$ and constitute $2.1 \%$ of all meningiomas. ${ }^{9}$ They are found almost exclusively as convexity tumor. ${ }^{10}$ Martin et $\mathrm{al}^{9}$ classified angiomatous meningioma into two patterns based on the diameter of vessels as macrovascular with $>50 \%$ of vessels having larger than $30 \mu \mathrm{m}$ in diameter and microvascular subtype in which $>50 \%$ of vessels were smaller than $30 \mu \mathrm{m}$ in diameter. It is the microvascular pattern, which can be confused with hemangioblastoma. Large series on angiomatous meningioma by Nolte and Paulus ${ }^{5}$ and Liu et $\mathrm{al}^{11}$ confirm the same findings. The current case had both angiomatous and cystic patterns, both of which rarely occur in meningiomas.

Although angiomatous meningiomas belong to WHO grade I, higher degree of peritumoral edema is observed very often. Angiomatous meningiomas also show isointensity or hyperintensity to the cerebral cortex on MRI. 


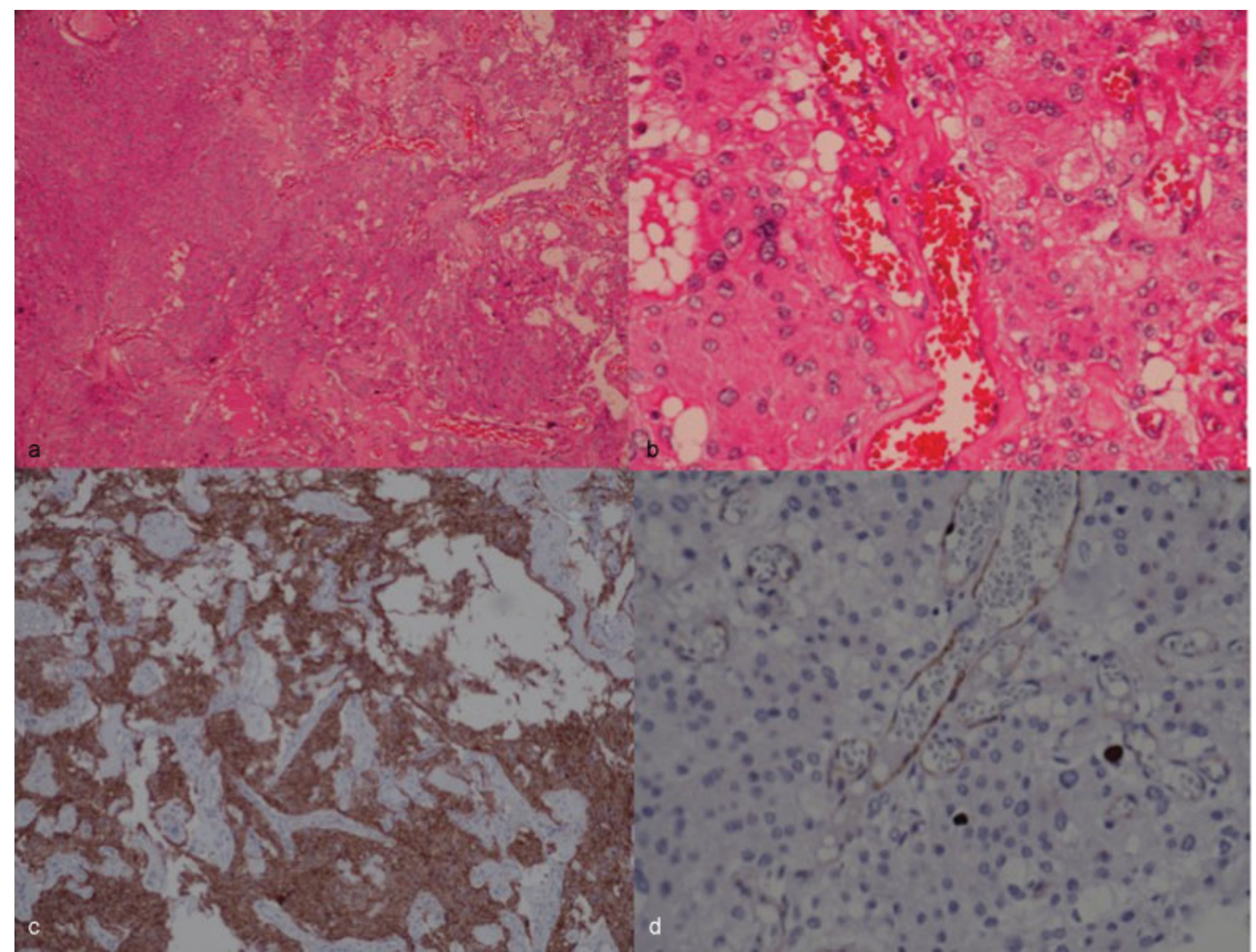

Fig. 3 (a) Neoplastic meningothelial cells in sheets and syncytium (H\&E: $\times 100)$, (b) vascular channels of varied caliber and focal lipomatous change are seen interspersed among the tumor cells (H\&E: $\times 400)$, (c) the tumor cells show diffuse membrane positivity for EMA, (d) Low MIB-1 index of $1.5 \%$. EMA, epithelial membrane antigen; $\mathrm{H} \& \mathrm{E}$, hematoxylin and eosin stain.

The radiological features of a large cyst with contrast-enhancing mural nodule mimic features of hemangioblastoma. The preoperative appearance of cystic meningioma and supratentorial hemangioblastoma may be indistinguishable. Although both angiomatous meningioma and hemangioblastoma are classified as benign neoplasms (WHO grade I) and the distinction between them seems to be irrelevant for therapeutic purpose. It is important for the patients with the occurrence of supratentorial hemangioblastoma, which almost always implies the diagnosis of Von Hippel-Lindau disease. ${ }^{12}$ However, recent reports have shown the usefulness of diffusion-weighted MRI in differentiating angiomatous meningioma from highly vascular tumor such as hemangiopericytoma. ${ }^{13}$

In this, the histological evidence of meningothelial tumor cells suggested a diagnosis of angiomatous meningioma. The accompanying large cysts could be regarded as secondary changes related to vascular permeability and transudation of plasma fluid resulting in micro- and macrocavitation of the tissue; a similar mechanism for the formation of cysts has been previously postulated in microcystic and richly vascularized meningiomas. ${ }^{14}$

\section{Conclusion}

Cystic angiomatous meningioma should be kept in the differential diagnosis of supratentorial solid cystic lesions along with other cystic tumors including hemangioblastoma. Long-term outcome after total excision of angiomatous meningioma is good.

\section{Conflict of Interest}

None.

\section{References}

1 Carvalho GA, Vorkapic P, Biewener G, Samii M. Cystic meningiomas resembling glial tumors. Surg Neurol 1997;47(3): 284-289, discussion 289-290

2 Borovich B, Guilburd JN, Doron Y, et al. Cystic meningiomas. Acta Neurochir Suppl (Wien) 1988;42:147-151

3 Parisi G, Tropea R, Giuffrida S, Lombardo M, Giuffrè F. Cystic meningiomas. Report of seven cases. J Neurosurg 1986;64(1):35-38

4 Sridhar K, Ravi R, Ramamurthi B, Vasudevan MC. Cystic meningiomas. Surg Neurol 1995;43(3):235-239 
5 Nolte KW, Paulus W. Angiomatous meningioma: a clinicopathologic study of 40 cases (abstr). Acta Neuropathol 2000; 99:453

6 Taraszewska A, Bogucki J. A case of cystic form of angiomatous meningioma with prominent microvascular pattern mimicking haemangioblastoma. Folia Neuropathol 2001;39(2):119-123

7 Deb P, Sahni H, Bhatoe HS. Cystic angiomatous meningioma in the cerebellopontine angle mimicking hemangioblastoma. J Cancer Res Ther 2010;6(4):560-563

8 Louis DN, Ohgaki H, Wiestler OD, et al. The 2007 WHO classification of tumours of the central nervous system. Acta Neuropathol 2007;114:97-109

9 Martin H, Kay WN, Werner P. Angiomatous meningioma:a clinicopathologic study of 38 cases. Am J Surg Pathol 2004; 28:390-393
10 Jellinger K, Slowik F. Histological subtypes and prognostic problems in meningiomas. J Neurol 1975;208(4):279-298

11 Liu Z, Wang C, Wang H, Wang Y, Li JY, Liu Y. Clinical characteristics and treatment of angiomatous meningiomas: a report of 27 cases. Int J Clin Exp Pathol 2013;6(4):695-702

12 Lee KR, Kishore PR, Wulfsberg E, Kepes JJ. Supratentorial leptomeningeal hemangioblastoma. Neurology 1978;28(7): 727-730

13 Meng Y, Chaohu W, Yi L, Jun P, Songtao Q. Preoperative radiologic characters to predict hemangiopericytoma from angiomatous meningioma. Clin Neurol Neurosurg 2015;138:78-82

14 Kuchna I, Matyja E, Wierzba-Bobrowicz T, Mazurowski W. Microcystic meningioma-a rarely occurring morphological variant of meningioma. Folia Neuropathol 1994;32(4): 259-263 